\title{
In situ hybridisation for the identification of Helicobacter pylori in paraffin wax embedded tissue
}

\author{
M S Bashir, F A Lewis, P Quirke, A Lee, M F Dixon
}

\begin{abstract}
A method for identifying Helicobacter pylori using a non-isotopic in situ hybridisation technique is described. A probe generated by polymerase chain reaction (PCR) with primers directed against parts of the Helicobacter pylori 16SrRNA sequence was used. Paraffin wax embedded gastric biopsy specimens from patients with and without gastritis were hybridised with the probe, and the method was shown to be sensitive and specific for $H$ pylori.
\end{abstract}

(F Clin Pathol 1994;47:862-864)

The association of a bacterial agent with gastritis was first recognised in $1983,{ }^{1}$ although a curved bacterium had been observed in the stomach of man as early as 1893 . The bacterium, initially called Campylobacter pyloridis, has been reclassified and named Helicobacter pylori, and is now well established as the major aetiological agent in gastritis and peptic ulcer. ${ }^{2}$ Several biopsy based methods have been used to identify Helicobacter including culture, ${ }^{3}$ histochemical stains, ${ }^{14}$ urease tests, ${ }^{5}$ hybridisation techniques, ${ }^{67}$ and the polymerase chain reaction. ${ }^{8}$

After eradication of $H$ pylori, early relapse is generally attributed to proliferation of small numbers of residual organisms which escape detection by conventional means so that histology and culture after treatment can be falsely negative. The use of a sensitive and specific method for the detection of small numbers of organisms that might be present is required in these cases.

\section{Methods}

The primers used for preparing the 109 base pair polymerase chain reaction (PCR) product were selected by comparing the sequence for $H$ pylori and related organismsthat is, Wolinella succinogenes, $H$ felis, $H$ mustelae and other Campylobacter species-which have been shown to be specific for $H$ pylori. ${ }^{8}$

A biotinylated 109 base pair PCR product of a 16SrRNA sequence (fig 1) of $H$ pylori $^{8}$ was generated by mixing together $10 \mu \mathrm{l}$ of $10 \times$ PCR reaction buffer (100 mM TRIS $\mathrm{HCl}$ (pH9.2), $500 \mathrm{mM} \mathrm{KCl,} 0 \cdot 1 \%$ gelatin and $1.0 \%$ Triton-X100), 20 pmol each of dATP, dCTP, dGTP, 20 pmol of a mixture of dTTP and biotin-11-dUTP (Sigma Chemical Co Ltd, Poole, Dorset) in a ratio of 3 to $1,50 \mathrm{pmol}$ each of primers HP1 and HP2, 1 ng of DNA extracted from an $H$ pylori culture and 1 unit of Supertaq DNA polymerase (HT Biotech, Cambridge) in a final volume of $100 \mu \mathrm{l}$ in molecular biology grade water (Merck Ltd, Lutterworth, Leicestershire). The reaction mixture was subjected to thermal cycling at $94^{\circ} \mathrm{C}$ for five minutes and $60^{\circ} \mathrm{C}$ for 30 seconds, for one cycle, $94^{\circ} \mathrm{C}$ for 30 seconds and $60^{\circ} \mathrm{C}$ for 30 seconds for 39 cycles, followed by a final incubation at $72^{\circ} \mathrm{C}$ for five minutes in an $\mathrm{MJ}$ Research Programmable Thermal Controller (Genetic Research Instrumentation Ltd, Felsted, Essex). The products from several PCR reactions were pooled and spun through a Microcon microconcentrator (Amicon Ltd, Stonehouse, Gloucestershire) at $12000 \times g$ for five minutes to remove excess primer. The PCR product was precipitated with 0.1 volume of $3 \mathrm{M}$ sodium acetate $(\mathrm{pH} 5.3)$ and 2.5 volumes of ethanol at $-20^{\circ} \mathrm{C}$ overnight. The DNA was recovered by centrifugation at $15000 \times g$ for 10 minutes, washed with $70 \%$ ethanol, and dried in a vacuum desiccator for 10 minutes. The biotinylated PCR product was dissolved in $50 \mu \mathrm{l}$ of molecular biology grade water; $2 \mu \mathrm{l}$ were used for quantitation by fluorometry using a mini-DNA fluorometer (Hoefer Scientific Newcastle-under-Lyme, Staffordshire) and $5 \mu \mathrm{l}$ were analysed on a $2 \%$ agarose gel to ensure that the 109 base pair product was present and free of contaminating bands. The remainder of the pooled product was adjusted to a final concentration of $10 \mu \mathrm{g} / \mathrm{ml}$ with molecular biology grade water and stored in $100 \mathrm{ng}$ aliquots at $-20^{\circ} \mathrm{C}$.

For in situ hybridisation gastric biopsy specimens from eight cases of Helicobacterassociated gastritis and five histologically normal $H$ pylori negative cases were used. The biopsy specimens had been routinely fixed in $10 \%$ formalin. Sections ( $5 \mu \mathrm{m}$ thick) were mounted on to aminoalkylsilane coated single well slides and hot plated for three days before dewaxing and rehydration through graded alcohols to water. The sections were treated sequentially with $0.02 \mathrm{M} \mathrm{HCl}$ for 10 minutes, $0.01 \%$ Triton-X100 for three minutes, $10 \%$ hexadecyltrimethylammonium

Primer sequences $\left(5^{\prime}-3^{\prime}\right)$ :

HP1 = CTG GAG AGA CTA AGC CCT CC HP2 = ATT ACT GAC GCT GAT TGT GC

Figure 1 Primer sequences from $H$ pylori $16 S r R N A$ region used for generating a 109 base pair probe by PCR. 
bromide (CTAB) in $0.7 \mathrm{M}$ sodium chloride for five minutes and digested with $0.5 \mathrm{mg} / \mathrm{ml}$ proteinase $\mathrm{K}$ in $50 \mathrm{mM}$ TRIS- $\mathrm{HCl}(\mathrm{pH} 7 \cdot 6)$, $5 \mathrm{~mm}$ EDTA at $37^{\circ} \mathrm{C}$ for 10 minutes. The sections were incubated in $20 \%$ acetic acid at $4^{\circ} \mathrm{C}$ for 15 seconds and postfixed in $4 \%$ paraformaldehyde in phosphate buffered saline before being dehydrated through graded alcohols to ethanol. The dried sections were covered with $75 \mu$ l of the biotinylated PCR generated probe for $H$ pylori containing $200 \mathrm{ng}$ probe $/ \mathrm{ml}$ in a hybridisation buffer containing $2 \times$ SSC $(1 \times$ SSC $=0.14 \mathrm{M}$ sodium chloride, $0.014 \mathrm{M}$ sodium citrate), $5 \%$ dextran sulphate, and $0.2 \%$ milk powder. The slides were covered with a piece of Gel Bond (Flowgen Instruments Ltd, Sittingbourne, Kent), sealed with nail varnish, and incubated at $98^{\circ} \mathrm{C}$ for 10 minutes to denature the probe and cellular DNA. The slides were incubated overnight at $37^{\circ} \mathrm{C}$ and washed three times in $2 \times \mathrm{SSC}$ at room temperature for 10 minutes-each wash to remove excess probe and mismatched hybrids. The biotin labelled hybridisation product was detected by using a biotin-streptavidin-alkaline phosphatase sandwich technique, as described before. ${ }^{9}$ Negative and positive controls were run with each batch. The specificity was confirmed by running parallel controls of paraffin wax embedded mouse gastric mucosa infected with the closely related organisms $H$ felis and Gastrospirillum hominis.

\section{Results}

Preliminary experiments were carried out to optimise digestion times with proteinase $\mathrm{K}$ and CTAB. Digestion times ranging from five

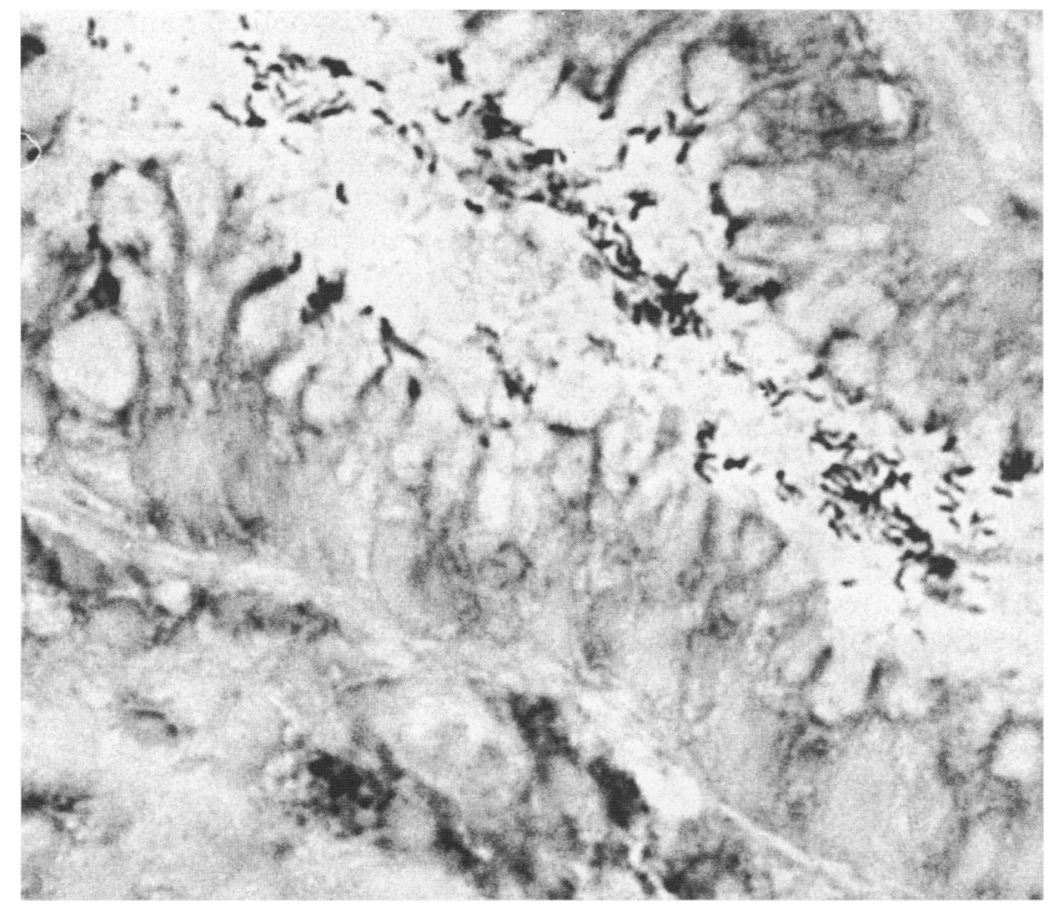

Figure $2 H$ pylori on the luminal aspect of gastric epithelial cells (in situ hybridisation using $H$ pylori probe). to 30 minutes were tried, and five minutes with $10 \%$ CTAB and 10 minutes with 0.5 $\mathrm{mg} / \mathrm{ml}$ proteinase $\mathrm{K}$ were found to give optimal signal with minimal background. A total human DNA probe was used as a positive control for the method; the negative control was treated with the hybridisation buffer only.

All eight cases of Helicobacter-associated gastritis demonstrated positive staining organisms with the morphology of $H$ pylori on the luminal aspect of surface epithelial cells and in the pits (fig 2). No signal was detected in the lamina propria. All five histologically normal gastric biopsy specimens failed to demonstrate any signal on in situ hybridisation.

The specificity was confirmed by the absence of signal in the negative controls and the paraffin wax embedded mouse gastric mucosa infected with $H$ felis and $G$ hominis.

\section{Discussion}

Several molecular biological techniques have been described for the identification of $H$ pylori, including hybridisation with radioactively and non-radioactively labelled genomic and cloned DNA probes, ${ }^{10}$ in situ hybridisation, ${ }^{6}$ and PCR. ${ }^{8}$ In situ hybridisation offers the advantage of preserving tissue morphology and being sensitive enough to permit detection of even a small number of organisms. Van den Berg et al described an ISH method for $H$ pylori. ${ }^{6}$ They used the entire $H$ pylori genome as a DNA probe and studied multiple biopsy specimens from one patient. In addition to using this restricted material, the probe was not tested against other Helicobacter $\mathrm{sp}$ in tissue sections and crossreacted with surface epithelial membrane. We used a biotinylated 109 base pair probe directed against part of the $H$ pylori $16 \mathrm{SrRNA}$ sequence as $H$ pylori was classified on the basis of such sequences. This probe is more specific and shows no cross-reaction with gastric epithelial cells. We studied a number of patients with and without Helicobacter-associated gastritis, and tested the specificity of the probe by running parallel controls of paraffin wax embedded mouse gastric mucosa infected with the closely related organisms $H$ felis and $G$ hominis.

Helicobacter pylori organisms were demonstrated on the luminal aspect of the surface and foveolar epithelium in all eight cases of $H$ pylori associated gastritis. The digestion times with CTAB and proteinase $K$ are critical as loss of morphology due to section digestion can occur. These were optimised for maximal signal with minimal background. The specificity of the technique was confirmed by the absence of a signal in the infected mouse gastric mucosa. Therefore, the in situ hybridisation technique that we used offers a sensitive and specific method for the detection of $H$ pylori in tissue sections. In situ hybridisation may thus be suitable for identifying the small number of $H$ pylori organisms that may be present in patients who relapse after apparent eradication, and which are currently deemed to be "negative" using routine histological stains. 
1 Warren JR. Unidentified curved bacilli on gastric epithelium in active chronic gastritis. Lancet 1983;i:1273-5.

2 Dixon MF. Helicobacter pylori and chronic gastritis. In Rathbone BJ, Heatley RV, eds. Helicobacter pylori and Rastroduodenal disease Second edn. Oxford: Blackwell Scientific, 1992:124-39.

3 Goodwin CS, Blincow ED, Warren JR, Waters TE, Sanderson LR, Easton T. Evaluation of culture techniques for isolating Campylobacter pyloridis from endoniques for isolating Campylobacter pyloridis from endo-
scopic biopsies of gastric mucosa. F Clin Pathol 1985;38:

4 Engstrand L, Pahlson C, Gustavsson S, Schwan A Monoclonal antibodies for rapid detection of Campylobacter pyloridis. Lancet 1986;ii:1403-5.

5 McNulty CAM, Dent JC, Uff JS, Gear MWL, Wilkinson SP. Detection of Campylobacter pylori by the biopsy urease test-an assessment in 1445 patients. Gut 1989; 30:1058-62.

6 Van den Berg FM, Zijlmans H, Langenberg W, Rauws E,
Schipper M. Detection of Campylobacter pylori in stomach tissue by DNA in situ hybridisation. $\mathcal{F}$ Clin Pathol 1989;42:995-1000.

7 Morotomi M, Hoshima S, Green P, Neu HC, Logerfo P, Watanabe I, et al. Oligonucleotide probe for detection and identification of Campylobacter pylori. $f \mathrm{Clin}$ Microbiol 1989;27:2652-5.

8 Ho SA, Hoyle JA, Lewis FA, Qurke P. Direct polymerase chain reaction test for detection of Helicobacter pylori in humans and animals. $f$ Clin Microbiol 1991;29: in humans

9 Lewis FA, Griffiths S, Dunicliffe R, Wells M, Dudding N, Bird CC. Sensitive in-situ hybridisation technique using biotin streptavidin polyalkaline phosphatase complex. $\mathcal{F}$ Clin Pathol 1987;40:163-6.

10 Wetherall BL, McDonald PJ, Johnson AM. Detection of Campylobacter pylori DNA by hybridisation with nonradioactive probes in comparison with a $\mathrm{P}^{32}$ labelled probe. $₹$ Med Microbiol 1988;26:257-63.

\title{
Mesenchymal hamartoma of liver in a man: Comparison with cases in infants
}

\author{
K Y Chau, J W C Ho, P C Wu, W K Yuen
}

\begin{abstract}
A 53 year old man with a large mesenchymal hamartoma is reported. Only a few bile ducts could be found in the periphery of the lesion and no hepatocytes were identified within the lesion. As far as is known, this is the only adult male patient reported to date. On the basis of the reported findings of mesenchymal hamartoma in other adults, it is suggested that there could be changes in the morphology of this lesion with age: progressive loss of hepatocytes; degeneration of bile duct epithelium; and cystic change of the mesenchymal component. The haematopoietic element is considered to be part of the fetal hepatic haematopoiesis that occurs in the hamartoma.
\end{abstract}

$(\mathcal{F}$ Clin Pathol 1994;47:864-866)

Department of Pathology, University of Hong Kong $\mathrm{K}$ Y Chau

P C Wu

\section{Department of}

Surgery, Queen Mary

Hospital, Hong Kong

JW C Ho

W K Yuen

Correspondence to:

Dr K Y Chau, Department of Pathology, University of Hong Kong, Pokfulam, Hong Kong

Accepted for publication 28 February 1994
Mesenchymal hamartoma is a rare lesion of the liver, occurring almost exclusively in young children. It seldom presents beyond the age of 5 , the average being 10 to 15 months. Presentation at birth has also been reported. The male to female ratio was found to be $2: 1$ in one study, but other series have shown an equal sex incidence. It is usually large and discovered as a progressively enlarging abdominal mass. Histologically it consists of myxoid and oedematous connective tissue with dilated vessels, lymphatics, and bile ducts. Clusters of hepatocytes and scattered haematopoietic cells are also often seen.

\section{Case report}

A 53 year old Chinese man was admitted into Queen Mary Hospital, Hong Kong, complaining of dull-aching right upper quadrant pain with fever which he had had for one day. His health had been good. He was found to have an enlarged liver about $10 \mathrm{~cm}$ below the xiphisternum. There was tenderness but no guarding or rebound. Laboratory investigations showed no abnormalities. Abdominal ultrasonography and a computed tomography scan showed a $20 \times 14 \times 10 \mathrm{~cm}$ heterogeneous hypodense lesion in the right lobe of the liver with well defined, irregular, curved band-shaped density areas. The caudate lobe was affected and the left lobe was displaced laterally. Contrast injection showed irregular marginal enhancement. Angiography (hepatic, superior mesenteric, and right renal) showed that the mass was hypovascular with no arterio-venous shunting. The main portal vein, inferior vena cava, and the right kidney were displaced but not affected.

A laparotomy was performed and a large soft mass replacing the right lobe was resected. The patient was well two years after the operation with no evidence of recurrence on ultrasound examination.

The resected lobe weighed $1520 \mathrm{~g}$ and measured $27 \times 15 \times 13 \mathrm{~cm}$. There was a well circumscribed tumour measuring $20 \mathrm{~cm}$ at its largest diameter. The cut surface showed soft, greyish, oedematous tumour tissue with extensive cystic change. The cysts were filled with clear fluid. There was no necrosis, calcification, or haemorrhage (fig 1).

Histological examination showed loosely 